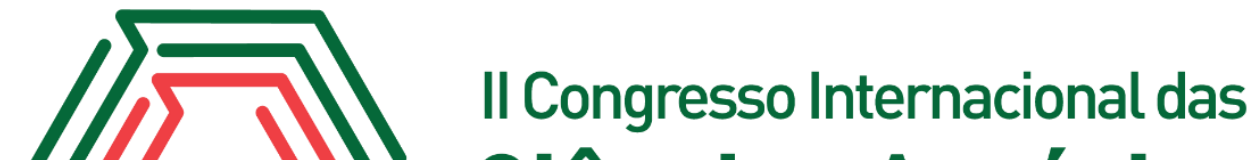 Ciências Agrárias COINTER - PDVAgro 2017
}

\section{PRODUÇÃO SUSTENTÁVEL NO SEMIÁRIDO FOCADA NO DESENVOLVIMENTO DE RENDA ATRAVÉS DA IMPLANTAÇÃO DA FEIRA DE AGROECOLÓGICOS EM JUAZEIRO DO NORTE-CE.}

\author{
Marcos Silva Tavares ${ }^{1}$; Leandro Alves Pinto ${ }^{2}$; Jurandi Antonio Berto ${ }^{3}$; Geovani de Oliveira \\ Tavares $^{4}$
}

\section{Introdução}

O Semiárido brasileiro ocupa uma parcela relevante da Região Nordeste do Brasil, onde as adversidades ambientais provocam sérias limitações no processo produtivo das populações, particularmente daqueles que compõem o conjunto dos pequenos agricultores, que desenvolvem agricultura familiar (CARVALHO, 2003). Porém, a convivência com o semiárido sugere o desenvolvimento da região, valorizando as potencialidades do local, seus conhecimentos tradicionais, a produção e conservação dos recursos naturais como fatores de permanência desses agricultores na zona rural. Observa-se, na temática de fertilidade do solo, um potencial regional aceitável de nutrientes e uma razoável disponibilidade de água no local, em virtude de o cultivo predominar as margens de um açude: Açude Manuel Balbino, também conhecido como Açude dos Carneiros, Suas obras foram realizadas pelo Departamento Nacional de Obras Contra a Seca (DNOCS), sendo concluído em 1985. Sua capacidade é de $37.180 .000 \mathrm{~m}^{3}$. Nesse contexto, implantar hortas agroecológicas visa produzir renda para os moradores, visto que, alimentos ecologicamente saudáveis promovem segurança alimentar, além de possuir diferenciação de valor no mercado. Esse estudo tem como objetivo demonstrar formas alternativas de convivência com o semiárido relatado pelos moradores da comunidade Z-60, açude dos carneiros, localizada no município de Juazeiro do Norte, CE, no decorrer do ano de 2016.

\section{Fundamentação Teórica}

\footnotetext{
${ }^{1}$ Engenharia Agronômica, Universidade Federal do Cariri - UFCA, marcosufca@outlook.com

${ }^{2}$ Engenharia Agronômica, Universidade Federal do Cariri - UFCA, leandro2015.2@hotmail.com

${ }^{3}$ Engenharia Agronômica, Universidade Federal do Cariri - UFCA, jurandiantonio@hotmail.com

${ }^{4}$ Professor Doutorando, Universidade Federal do Cariri - UFCA, geovani.tavares@ufca.edu.br
} 
O perfil municipal do Semiárido mostra que dos $42 \%$ dos municípios têm menos de 10.000 habitantes, a taxa de urbanização de 45\%. (GOMES FILHO, 2003)

Os processos de exploração agrícola, em regime de agricultura irrigada ou de agricultura de sequeiro, como também as expansões da pecuária, em bases mais modernas, têm contribuído para produzir impactos ambientais capazes de potenciar os processos de desertificação. (MMA, 2004). A ampliação no acesso à educação, especialmente a partir do ano 2000 permitiu, indiscutivelmente, uma visão futurista do que é viável se fazer para evitar o êxodo rural, especialmente na região focada nesse trabalho, bem como da ênfase no contexto de cultivo sustentável, sendo primordial nos cuidados com o meio ambiente.

As políticas públicas de desenvolvimento regional nasceram de grandes propostas nacionais, oriundas de uma elite dirigente que se impunha à missão de combater as disparidades, integrar economicamente as regiões e fortalecer os vínculos da comunidade nacional: o ideal de nação, povo, identidade regional. (ZAIDAN FILHO, 2001). Evidentemente, as crescentes ações educacionais, políticas e da própria população enxergam, além de uma dificuldade, promissoras oportunidades de permanência das pessoas na região Nordeste.

\section{Metodologia}

O projeto foi uma ação da Universidade Federal do Cariri-UFCA, através da Pró-reitoria de extensão PROEX. Inicialmente, foi feito uma análise das pretensões dos agricultores da comunidade, quantificadas as famílias/produtores individuais a nível de culturas e em seguida confeccionado um cronograma com os ciclos das culturas e escalonamento que seriam feitos entre os agricultores. Optou-se, em função das características físicas do solo, por cebola, alface, coentro, beterraba, pepino, berinjela, tomate cereja, repolho e outros. Além disso, produtos caseiros com doces, ovos, plantas ornamentais e um minhocário foram implantados com intuito de ampliar a renda. Os produtos foram direcionados para comercialização em feiras de agroecológicos nas cidades de Juazeiro do Norte, Caririaçu, e ainda, comercializados no Cariri Garden Shopping em Juazeiro, onde houve maior valorização dos produtos pelos compradores.

\section{Resultados e Discussões}

A atuação da universidade no desenvolvimento rural sustentável proporcionou melhorias significativas na produção e teve os objetivos alcançados. A presente demanda por alimentos 
saudáveis fez com que os produtores fossem felizes nas vendas. A produção, atualmente, está sendo uma demanda na região e servindo de modelo para várias comunidades vizinhas, que por sinal, algumas foram ter uma vivência no plantio agroecológico da comunidade Z-60, proporcionada pela UFCA.

Os produtores conseguiram, em média, uma renda mensal de $\mathrm{R} \$ 350,00$, sendo que maioria obtiveram resultados ainda mais positivos $>\mathrm{R} \$ 400,00$. Os produtores diferenciados compreendem aqueles que buscaram maior diversidade de produtos.
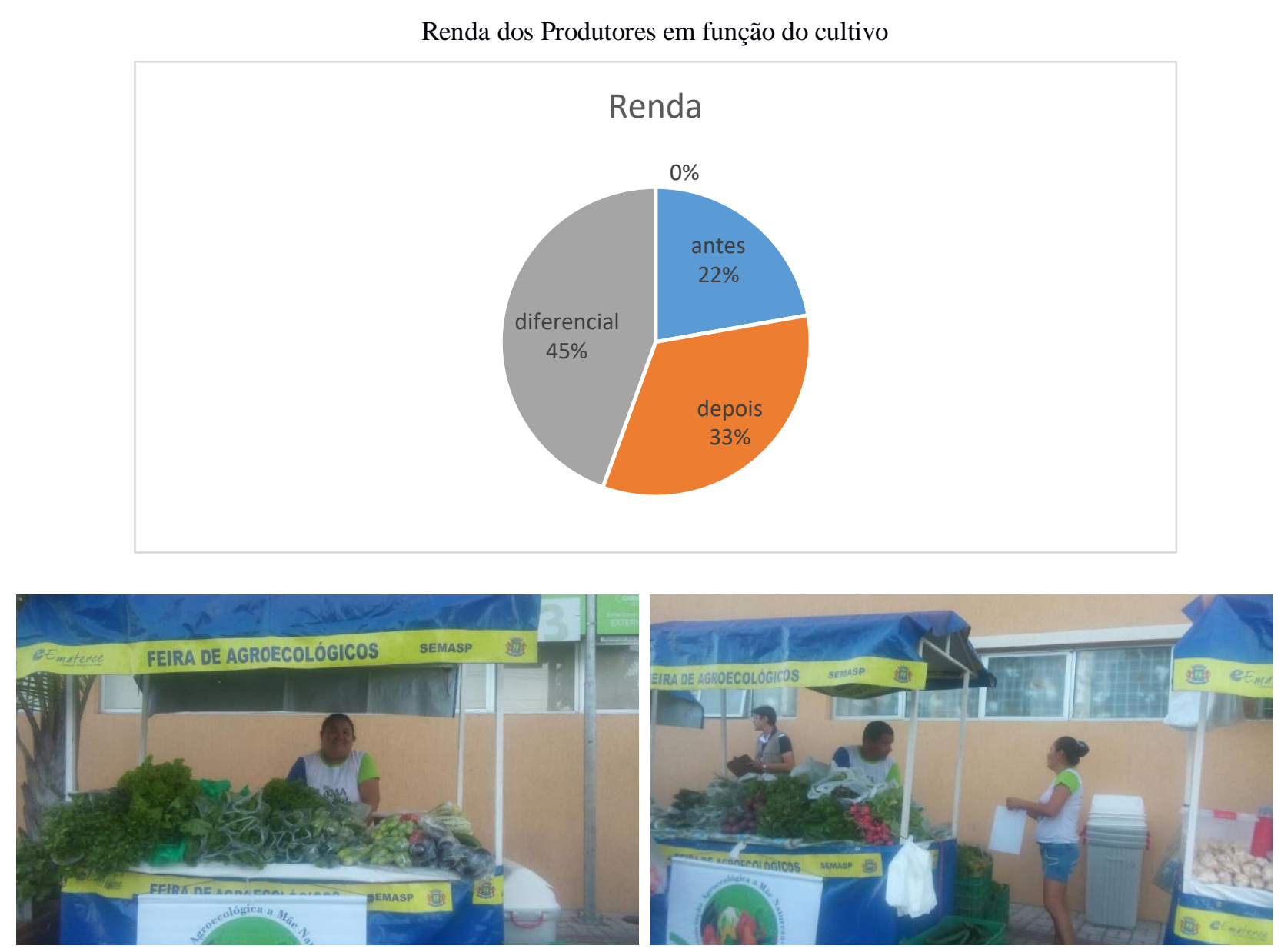

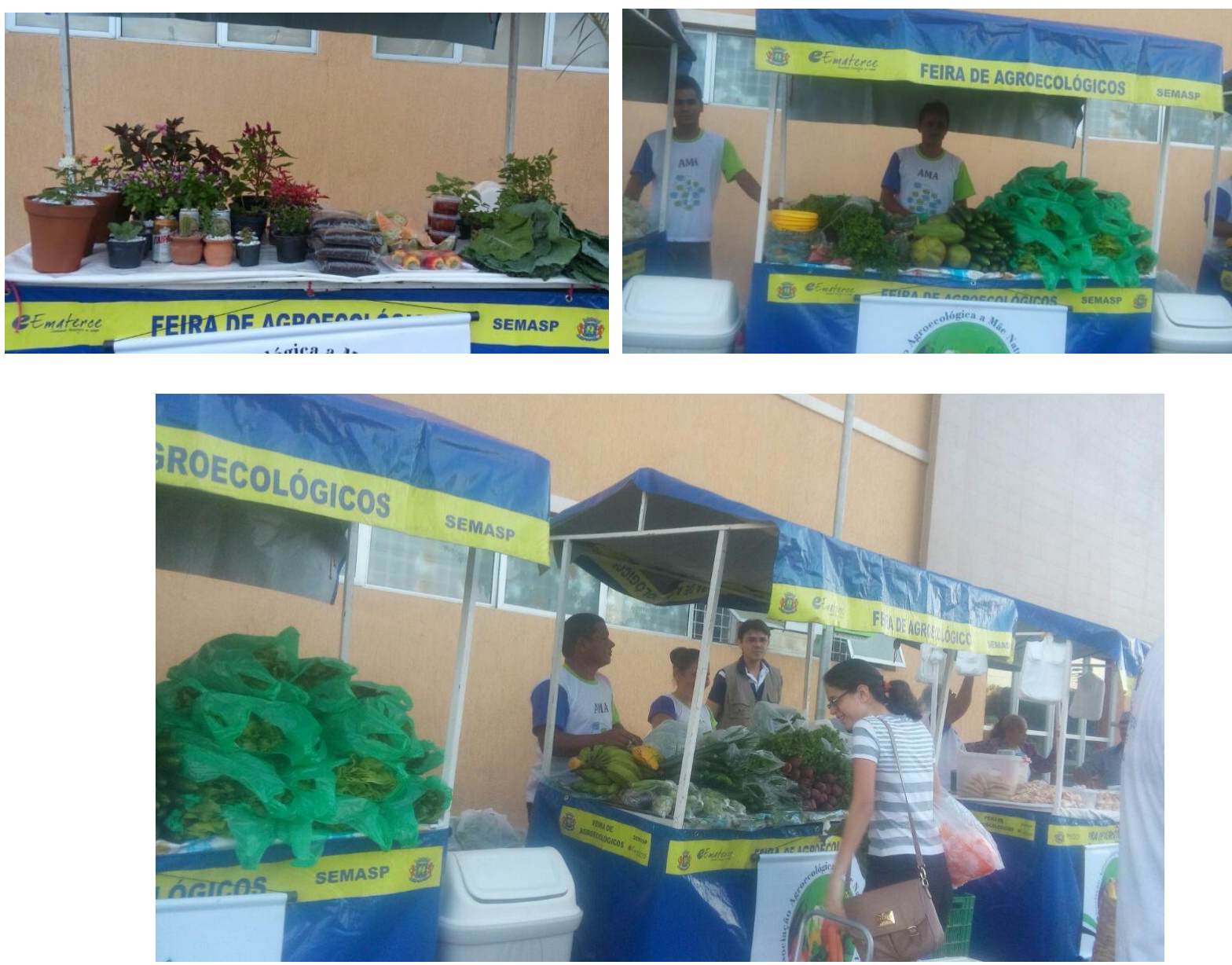

\section{Conclusões}

O trabalho impactou positivamente a comunidade, proporcionando lucros. A atividade do projeto se encontra em expansão, buscando novos mercados em cidades vizinhas e agregando mais pessoas nesse processo.

\section{Referências}


CARVALHO, Otamar de. Nordeste: Desenvolvimento e Convivência com a Semiaridez. Relatório Preliminar - Ministério da Integração Nacional - Secretaria de Políticas de Desenvolvimento Regional - Gti-Grupo de Trabalho Interministerial para a Recriação da Sudene, Recife, 2003. 